\title{
Existence and uniqueness of a positive periodic solution for Rayleigh type $\phi$-Laplacian equation
}

Yun Xin $^{1 *}$ and Zhibo Cheng ${ }^{2}$

\section{"Correspondence:}

xy_1982@126.com

${ }^{1}$ College of Computer Science and

Technology, Henan Polytechnic

University, Jiaozuo, 454000, China

Full list of author information is

available at the end of the article

\begin{abstract}
By using the Manásevich-Mawhin continuation theorem and some analysis skills, we establish some sufficient condition for the existence and uniqueness of positive $T$-periodic solutions for a generalized Rayleigh type $\phi$-Laplacian operator equation. The results of this paper are new and they complement previous known results. MSC: $34 \mathrm{~K} 13 ; 34 \mathrm{C} 25$
\end{abstract}

Keywords: positive periodic solution; uniqueness; $\phi$-Laplacian; Rayleigh equation

\section{Introduction}

During the past few years, many researchers have discussed the periodic solutions of a Rayleigh type differential equation (see [1-10]). For example, in 2009, Xiao and Liu [7] studied the Rayleigh type $p$-Laplacian equation with a deviating argument of the form

$$
\left(\phi_{p}\left(x^{\prime}(t)\right)\right)^{\prime}+f\left(t, x^{\prime}(t)\right)+g(t, x(t-\tau(t)))=e(t) .
$$

By using the coincidence degree theory, we establish new results on the existence of periodic solutions for the above equation. Afterward, Xiong and Shao [9] used the coincidence degree theory to establish new results on the existence and uniqueness of positive $T$-periodic solutions for the Rayleigh type $p$-Laplacian equation of the form

$$
\left(\phi_{p}\left(x^{\prime}(t)\right)\right)^{\prime}+f\left(t, x^{\prime}(t)\right)+g(t, x(t))=e(t) .
$$

In this paper, we consider the following Rayleigh type $\phi$-Laplacian operator equation:

$$
\left(\phi\left(x^{\prime}(t)\right)\right)^{\prime}+f\left(t, x^{\prime}(t)\right)+g(t, x(t))=e(t),
$$

where the function $\phi: \mathbb{R} \rightarrow \mathbb{R}$ is continuous and $\phi(0)=0$. $f, g \in \operatorname{Car}(\mathbb{R} \times \mathbb{R}, \mathbb{R})$ is an $L^{p}$ Carathéodory function and $p=\frac{m}{m-1}, m \geq 2$, which means it is measurable in the first variable and continuous in the second variable. For every $0<r<s$, there exists $h_{r, s} \in L^{p}[0, T]$ such that $|g(t, x(t))| \leq h_{r, s}$ for all $x \in[r, s]$ and a.e. $t \in[0, T]$; and $f, g$ is a $T$-periodic function about $t$ and $f(t, 0)=0 . e \in L^{p}([0, T], \mathbb{R})$ and is $T$-periodic.

Here $\phi: \mathbb{R} \rightarrow \mathbb{R}$ is a continuous function and $\phi(0)=0$, which satisfies

o2014 Xin and Cheng; licensee Springer. This is an Open Access article distributed under the terms of the Creative Commons Attribution License (http://creativecommons.org/licenses/by/2.0), which permits unrestricted use, distribution, and reproduction in any medium, provided the original work is properly cited. 
$\left(\mathrm{A}_{1}\right)\left(\phi\left(x_{1}\right)-\phi\left(x_{2}\right)\right)\left(x_{1}-x_{2}\right)>0$ for $\forall x_{1} \neq x_{2}, x_{1}, x_{2} \in \mathbb{R} ;$

$\left(\mathrm{A}_{2}\right)$ there exists a function $\alpha:[0,+\infty] \rightarrow[0,+\infty], \alpha(s) \rightarrow+\infty$ as $s \rightarrow+\infty$, such that $\phi(x)$. $x \geq \alpha(|x|)|x|$ for $\forall x \in \mathbb{R}$.

It is easy to see that $\phi$ represents a large class of nonlinear operators, including $\phi_{p}: \mathbb{R} \rightarrow$ $\mathbb{R}$ is a $p$-Laplacian, i.e., $\phi_{p}(x)=|x|^{p-2} x$ for $x \in \mathbb{R}$.

We know that the study on $\phi$-Laplacian is relatively infrequent, the main difficulty lies in the fact that the $\phi$-Laplacian operator typically possesses more uncertainty than the $p$-Laplacian operator. For example, the key step for $\phi_{p}$ to get a priori solutions, $\int_{0}^{T}\left(\phi_{p}^{\prime}(x(t))\right)^{\prime} x(t) d t=-\int_{0}^{T}\left|x^{\prime}(t)\right|^{p} d t$, is no longer available for general $\phi$-Laplacian. So, we need to find a new method to get over it.

By using the Manásevich-Mawhin continuation theorem and some analysis skills, we establish some sufficient condition for the existence of positive $T$-periodic solutions of (1.1). The results of this paper are new and they complement previous known results.

\section{Main results}

For convenience, define

$$
C_{T}^{1}=\left\{x \in C^{1}(\mathbb{R}, \mathbb{R}): x \text { is } T \text {-periodic }\right\},
$$

which is a Banach space endowed with the norm $\|\cdot\|$; define $\|x\|=\max \left\{|x|_{0},\left|x^{\prime}\right|_{0}\right\}$ for all $x$, and

$$
|x|_{0}=\max _{t \in[0, T]}|x(t)|, \quad\left|x^{\prime}\right|_{0}=\max _{t \in[0, T]}\left|x^{\prime}(t)\right| .
$$

For the $T$-periodic boundary value problem

$$
\left(\phi\left(x^{\prime}(t)\right)\right)^{\prime}=\tilde{f}\left(t, x, x^{\prime}\right)
$$

here $\tilde{f}:[0, T] \times \mathbb{R} \times \mathbb{R} \rightarrow \mathbb{R}$ is assumed to be Carathéodory.

Lemma 2.1 (Manásevich-Mawhin [11]) Let $\Omega$ be an open bounded set in $C_{T}^{1}$. If

(i) for each $\lambda \in(0,1)$, the problem

$$
\left(\phi\left(x^{\prime}\right)\right)^{\prime}=\lambda \tilde{f}\left(t, x, x^{\prime}\right), \quad x(0)=x(T), \quad x^{\prime}(0)=x^{\prime}(T)
$$

has no solution on $\partial \Omega$;

(ii) the equation

$$
F(a):=\frac{1}{T} \int_{0}^{T} \tilde{f}\left(t, x, x^{\prime}\right) d t=0
$$

has no solution on $\partial \Omega \cap \mathbb{R}$;

(iii) the Brouwer degree of $F$

$$
\operatorname{deg}\{F, \Omega \cap \mathbb{R}, 0\} \neq 0 .
$$

Then the periodic boundary value problem (2.1) has at least one periodic solution on $\bar{\Omega}$.

Lemma 2.2 If $\phi(x)$ is bounded, then $x$ is also bounded. 
Proof Since $\phi(x)$ is bounded, then there exists a positive constant $N$ such that $|\phi(x)| \leq N$. From $\left(\mathrm{A}_{2}\right)$, we have $\alpha(|x|)|x| \leq \phi(x) \cdot x \leq|\phi(x)| \cdot|x| \leq N|x|$. Hence, we can get $\alpha(|x|) \leq N$ for all $x \in \mathbb{R}$. If $x$ is not bounded, then from the definition of $\alpha$, we get $\alpha(|x|)>N$ for some $x \in \mathbb{R}$, which is a contradiction. So $x$ is also bounded.

Lemma 2.3 Suppose that the following condition holds:

$\left(\mathrm{A}_{3}\right)\left(x_{1}-x_{2}\right)\left(g\left(t, x_{1}\right)-g\left(t, x_{2}\right)\right)<0$ for all $t, x_{1}, x_{2} \in \mathbb{R}, x_{1} \neq x_{2}$.

Then (1.1) has at most one $T$-periodic solution in $C_{T}^{1}$.

Proof Assume that $x_{1}(t)$ and $x_{2}(t)$ are two $T$-periodic solutions of (1.1). Then we obtain

$$
\left(\phi\left(x_{1}^{\prime}(t)\right)-\phi\left(x_{2}^{\prime}(t)\right)\right)^{\prime}+f\left(t, x_{1}^{\prime}(t)\right)-f\left(t, x_{2}^{\prime}(t)\right)+g\left(t, x_{1}(t)\right)-g\left(t, x_{2}(t)\right)=0 .
$$

Set $u(t)=x_{1}(t)-x_{2}(t)$. Now, we claim that

$$
u(t) \leq 0 \quad \text { for all } t \in \mathbb{R} .
$$

In contrast, in view of $x_{1}, x_{2} \in C^{1}[0, T]$, for $t \in \mathbb{R}$, we obtain

$$
\max _{t \in \mathbb{R}} u(t)>0 .
$$

Then there must exist $t^{*} \in \mathbb{R}$ (for convenience, we can choose $t^{*} \in(0, T)$ ) such that

$$
u\left(t^{*}\right)=\max _{t \in[0, T]} u(t)=\max _{t \in \mathbb{R}} u(t)>0,
$$

which implies that

$$
u^{\prime}\left(t^{*}\right)=x_{1}^{\prime}\left(t^{*}\right)-x_{2}^{\prime}\left(t^{*}\right)=0
$$

and

$$
x_{1}\left(t^{*}\right)-x_{2}\left(t^{*}\right)>0 \text {. }
$$

By hypothesis $\left(\mathrm{A}_{3}\right)$ and $(2.2)$, we have

$$
\begin{aligned}
\left(\phi\left(x_{1}^{\prime}\left(t^{*}\right)\right)-\phi\left(x_{2}^{\prime}\left(t^{*}\right)\right)\right)^{\prime}= & -\left[f\left(t^{*}, x_{1}^{\prime}\left(t^{*}\right)\right)-f\left(t^{*}, x_{2}^{\prime}\left(t^{*}\right)\right)\right] \\
& -\left[g\left(t^{*}, x_{1}\left(t^{*}\right)\right)-g\left(t^{*}, x_{2}\left(t^{*}\right)\right)\right] \\
= & -\left[g\left(t^{*}, x_{1}\left(t^{*}\right)\right)-g\left(t^{*}, x_{2}\left(t^{*}\right)\right)\right]>0,
\end{aligned}
$$

and there exists $\varepsilon>0$ such that $\left(\phi\left(x_{1}^{\prime}(t)\right)-\phi\left(x_{2}^{\prime}(t)\right)\right)^{\prime}>0$ for all $t \in\left(t^{*}-\varepsilon, t^{*}\right]$. Therefore, $\phi\left(x_{1}^{\prime}(t)\right)-\phi\left(x_{2}^{\prime}(t)\right)$ is strictly increasing for $t \in\left(t^{*}-\varepsilon, t^{*}\right]$, which implies that

$$
\phi\left(x_{1}^{\prime}(t)\right)-\phi\left(x_{2}^{\prime}(t)\right)<\phi\left(x_{1}^{\prime}\left(t^{*}\right)\right)-\phi\left(x_{2}^{\prime}\left(t^{*}\right)\right)=0 \quad \text { for all } t \in\left(t^{*}-\varepsilon, t^{*}\right) .
$$

From $\left(\mathrm{A}_{1}\right)$ we get

$$
u^{\prime}(t)=x_{1}^{\prime}(t)-x_{2}^{\prime}(t)<0 \quad \text { for all } t \in\left(t^{*}-\varepsilon, t^{*}\right) .
$$


This contradicts the definition of $t^{*}$. Thus,

$$
u(t)=x_{1}(t)-x_{2}(t) \leq 0 \quad \text { for all } t \in \mathbb{R} .
$$

By using a similar argument, we can also show that

$$
x_{2}(t)-x_{1}(t) \leq 0 .
$$

Therefore, we obtain

$$
x_{1}(t) \equiv x_{2}(t) \quad \text { for all } t \in \mathbb{R} \text {. }
$$

Hence, (1.1) has at most one $T$-periodic solution in $C_{T}^{1}$. The proof of Lemma 2.3 is now complete.

For the sake of convenience, we list the following assumptions which will be used repeatedly in the sequel:

$\left(\mathrm{H}_{1}\right)$ there exists a positive constant $D$ such that $g(t, x)-e(t)<0$ for $x>D$ and $t \in \mathbb{R}, g(t, x)-$ $e(t)>0$ for $x \leq 0$ and $t \in \mathbb{R}$;

$\left(\mathrm{H}_{2}\right)$ there exist constants $\sigma>0$ and $m \geq 2$ such that $f(t, u) u \geq \sigma|u|^{m}$ for $(t, u) \in[0, T] \times \mathbb{R}$;

$\left(\mathrm{H}_{3}\right)$ there exist positive constants $\rho$ and $\gamma$ such that $|f(t, u)| \leq \rho|u|^{m-1}+\gamma$ for $(t, u) \in$ $[0, T] \times \mathbb{R}$

$\left(\mathrm{H}_{4}\right)$ there exist positive constants $\alpha, \beta, B$ such that

$$
|g(t, x)| \leq \alpha|x|^{m-1}+\beta \quad \text { for }|x| \geq B \text { and } t \in \mathbb{R} .
$$

By using Lemmas 2.1-2.3, we obtain our main results.

Theorem 2.1 Assume that conditions $\left(\mathrm{H}_{1}\right)-\left(\mathrm{H}_{4}\right)$ and $\left(\mathrm{A}_{3}\right)$ hold. Then (1.1) has a unique positive T-periodic solution if $\sigma-\frac{\alpha T^{m-1}}{2^{m-1}}>0$.

Proof Consider the homotopic equation of (1.1) as follows:

$$
\left(\phi\left(x^{\prime}(t)\right)\right)^{\prime}+\lambda f\left(t, x^{\prime}(t)\right)+\lambda g(t, x(t))=\lambda e(t) .
$$

By Lemma 2.3, it is easy to see that (1.1) has at most one $T$-periodic solution in $C_{T}^{1}$. Thus, to prove Theorem 2.1, it suffices to show that (1.1) has at least one $T$-periodic solution in $C_{T}^{1}$. To do this, we are going to apply Lemmas 2.1 and 2.2. Firstly, we will claim that the set of all possible $T$-periodic solutions of (2.3) is bounded. Let $x(t) \in C_{T}^{1}$ be an arbitrary solution of (2.3) with period $T$. As $x(0)=x(T)$, there exists $t_{0} \in[0, T]$ such that $x^{\prime}\left(t_{0}\right)=0$, while $\phi(0)=0$, we see

$$
\begin{aligned}
\left|\phi\left(x^{\prime}(t)\right)\right| & =\left|\int_{t_{0}}^{t}\left(\phi\left(x^{\prime}(s)\right)\right)^{\prime} d s\right| \\
& \leq \lambda \int_{0}^{T}\left|f\left(t, x^{\prime}(t)\right)\right| d t+\lambda \int_{0}^{T}|g(t, x(t))| d t+\lambda \int_{0}^{T}|e(t)| d t,
\end{aligned}
$$

where $t \in\left[t_{0}, t_{0}+T\right]$. 
We claim that there is a constant $\xi \in \mathbb{R}$ such that

$$
|x(\xi)| \leq D
$$

Let $\bar{t}, \underline{t}$ be, respectively, the global maximum point and the global minimum point of $x(t)$ on $[0, T]$; then $x^{\prime}(\bar{t})=0$, and we claim that

$$
\left(\phi\left(x^{\prime}(\bar{t})\right)\right)^{\prime} \leq 0
$$

Assume, by way of contradiction, that (2.6) does not hold. Then $\left(\phi\left(x^{\prime}(\bar{t})\right)\right)^{\prime}>0$ and there exists $\varepsilon>0$ such that $\left(\phi\left(x^{\prime}(t)\right)\right)^{\prime}>0$ for $t \in(\bar{t}-\varepsilon, \bar{t}+\varepsilon)$. Therefore $\phi\left(x^{\prime}(t)\right)$ is strictly increasing for $t \in(\bar{t}-\varepsilon, \bar{t}+\varepsilon)$. From $\left(\mathrm{A}_{1}\right)$ we know that $x^{\prime}(t)$ is strictly increasing for $t \in(\bar{t}-\varepsilon, \bar{t}+\varepsilon)$. This contradicts the definition of $\bar{t}$. Thus, (2.6) is true. From $f(t, 0)=0,(2.3)$ and (2.6), we have

$$
g(\bar{t}, x(\bar{t}))-e(\bar{t}) \geq 0
$$

Similarly, we get

$$
g(\underline{t}, x(\underline{t}))-e(\underline{t}) \leq 0
$$

In view of $\left(\mathrm{H}_{1}\right),(2.7)$ and (2.8) imply that

$$
x(\bar{t}) \leq D, \quad x(\underline{t})>0 .
$$

Case (1): If $x(t) \in(0, D)$, define $\xi=\bar{t}$, obviously, $|x(\xi)| \leq D$.

Case (2): If $x(\underline{t}) \geq D$, from $x(\bar{t}) \leq D$, we know $x(\bar{t})=x(\underline{t})$. Define $\xi=\bar{t}$, we have $|x(\xi)|=D$. This proves (2.5).

Then we have

$$
|x(t)|=\left|x(\xi)+\int_{\xi}^{t} x^{\prime}(s) d s\right| \leq D+\int_{\xi}^{t}\left|x^{\prime}(s)\right| d s, \quad t \in[\xi, \xi+T]
$$

and

$$
|x(t)|=|x(t-T)|=\left|x(\xi)-\int_{t-T}^{\xi} x^{\prime}(s) d s\right| \leq D+\int_{t-T}^{\xi}\left|x^{\prime}(s)\right| d s, \quad t \in[\xi, \xi+T] .
$$

Combining the above two inequalities, we obtain

$$
\begin{aligned}
|x|_{0} & =\max _{t \in[0, T]}|x(t)|=\max _{t \in[\xi, \xi+T]}|x(t)| \\
& \leq \max _{t \in[\xi, \xi+T]}\left\{D+\frac{1}{2}\left(\int_{\xi}^{t}\left|x^{\prime}(s)\right| d s+\int_{t-T}^{\xi}\left|x^{\prime}(s)\right| d s\right)\right\} \\
& \leq D+\frac{1}{2} \int_{0}^{T}\left|x^{\prime}(s)\right| d s .
\end{aligned}
$$


Since $x^{\prime}(t)$ is $T$-periodic, multiplying $x^{\prime}(t)$ and (2.3) and then integrating it from 0 to $T$, we have

$$
\begin{aligned}
0 & =\int_{0}^{T}\left(\phi\left(x^{\prime}(t)\right)\right)^{\prime} x^{\prime}(t) d t \\
& =-\lambda \int_{0}^{T} f\left(t, x^{\prime}(t)\right) x^{\prime}(t) d t-\lambda \int_{0}^{T} g(t, x(t)) x^{\prime}(t) d t+\lambda \int_{0}^{T} e(t) x^{\prime}(t) d t .
\end{aligned}
$$

In view of (2.10), we have

$$
\left|\int_{0}^{T} f\left(t, x^{\prime}(t)\right) x^{\prime}(t) d t\right|=\left|-\int_{0}^{T} g(t, x(t)) x^{\prime}(t) d t+\int_{0}^{T} e(t) x^{\prime}(t) d t\right| .
$$

From $\left(\mathrm{H}_{2}\right)$, we know

$$
\left|\int_{0}^{T} f\left(t, x^{\prime}(t)\right) x^{\prime}(t) d t\right| \geq \sigma \int_{0}^{T}\left|x^{\prime}(t)\right|^{m} d t
$$

Set

$$
E_{1}=\{t \in[0, T]|| x(t) \mid \leq B\}, \quad E_{2}=\{t \in[0, T]|| x(t) \mid \geq B\} .
$$

From $\left(\mathrm{H}_{4}\right)$, we have

$$
\begin{aligned}
\sigma & \int_{0}^{T}\left|x^{\prime}(t)\right|^{m} d t \\
\leq & \int_{E_{1}+E_{2}}|g(t, x(t))|\left|x^{\prime}(t)\right| d t+\int_{0}^{T}|e(t)|\left|x^{\prime}(t)\right| d t \\
\leq & \left(\int_{E_{1}}|g(t, x(t))|^{\frac{m}{m-1}} d t\right)^{\frac{m-1}{m}}\left(\int_{0}^{T}\left|x^{\prime}(t)\right|^{m} d t\right)^{\frac{1}{m}}+\alpha \int_{0}^{T}|x(t)|^{m-1}\left|x^{\prime}(t)\right| d t \\
& +\beta \int_{0}^{T}\left|x^{\prime}(t)\right| d t+\int_{0}^{T}|e(t)|\left|x^{\prime}(t)\right| d t \\
\leq & \left|g_{B}\right| \frac{m}{m-1}\left(\int_{0}^{T}\left|x^{\prime}(t)\right|^{m} d t\right)^{\frac{1}{m}}+\alpha\left(D+\frac{1}{2} \int_{0}^{T}\left|x^{\prime}(t)\right| d t\right)^{m-1} \int_{0}^{T}\left|x^{\prime}(t)\right| d t \\
& +\beta T^{\frac{m-1}{m}}\left(\int_{0}^{T}\left|x^{\prime}(t)\right|^{m} d t\right)^{\frac{1}{m}}+\left(\int_{0}^{T}|e(t)|^{\frac{m}{m-1}}\right)^{\frac{m-1}{m}}\left(\int_{0}^{T}\left|x^{\prime}(t)\right|^{m} d t\right)^{\frac{1}{m}} \\
= & \left|g_{B}\right| \frac{m}{m-1}\left(\int_{0}^{T}\left|x^{\prime}(t)\right|^{m} d t\right)^{\frac{1}{m}}+\frac{\alpha}{2^{m-1}}\left(\frac{2 D}{\int_{0}^{T}\left|x^{\prime}(t)\right| d t}+1\right)^{m-1}\left(\int_{0}^{T}\left|x^{\prime}(t)\right| d t\right)^{m} \\
& +\beta T^{\frac{m-1}{m}}\left(\int_{0}^{T}\left|x^{\prime}(t)\right|^{m} d t\right)^{\frac{1}{m}}+|e|_{\frac{m}{m-1}}\left(\int_{0}^{\frac{1}{m}}\left|x^{\prime}(t)\right|^{m} d t\right)^{\prime}
\end{aligned}
$$

where $g_{B}=\max _{|x| \leq B}|g(t, x(t))|,\left|g_{B}\right|_{\frac{m}{m-1}}=\left(\int_{0}^{T}\left|g_{B}\right|^{\frac{m}{m-1}} d t\right)^{\frac{m-1}{m}}$.

For the constant $\delta>0$, which is only dependent on $k>0$, we have

$$
(1+x)^{k} \leq 1+(1+k) x \quad \text { for } x \in[0, \delta]
$$


Kin and Chen Advances in Difference Equations 2014, 2014:225

Page 7 of 10

So, from (2.11), we have

$$
\begin{aligned}
\sigma & \int_{0}^{T}\left|x^{\prime}(t)\right|^{m} d t \\
\leq & \left|g_{B}\right|_{\frac{m}{m-1}}\left(\int_{0}^{T}\left|x^{\prime}(t)\right|^{m} d t\right)^{\frac{1}{m}}+\frac{\alpha}{2^{m-1}}\left(1+\frac{2 D m}{\int_{0}^{T}\left|x^{\prime}(t)\right| d t}\right)\left(\int_{0}^{T}\left|x^{\prime}(t)\right| d t\right)^{m} \\
& +\beta T^{\frac{m-1}{m}}\left(\int_{0}^{T}\left|x^{\prime}(t)\right|^{m} d t\right)^{\frac{1}{m}}+|e|_{\frac{m}{m-1}}\left(\int_{0}^{T}\left|x^{\prime}(t)\right|^{m} d t\right)^{\frac{1}{m}} \\
= & \left|g_{B}\right|_{\frac{m}{m-1}}\left(\int_{0}^{T}\left|x^{\prime}(t)\right|^{m} d t\right)^{\frac{1}{m}}+\frac{\alpha}{2^{m-1}}\left(\int_{0}^{T}\left|x^{\prime}(t)\right| d t\right)^{m}+\frac{\alpha D m}{2^{m-2}}\left(\int_{0}^{T}\left|x^{\prime}(t)\right| d t\right)^{m-1} \\
& +\beta T^{\frac{m-1}{m}}\left(\int_{0}^{T}\left|x^{\prime}(t)\right|^{m} d t\right)^{\frac{1}{m}}+|e|_{\frac{m}{m-1}}\left(\int_{0}^{T}\left|x^{\prime}(t)\right|^{m} d t\right)^{\frac{1}{m}} \\
\leq & \left|g_{B}\right| \frac{m}{m-1}\left(\int_{0}^{T}\left|x^{\prime}(t)\right|^{m} d t\right)^{\frac{1}{m}}+\frac{\alpha T^{m-1}}{2^{m-1}} \int_{0}^{T}\left|x^{\prime}(t)\right|^{m} d t \\
& +\frac{\alpha D m T^{\frac{(m-1)^{2}}{m}}}{2^{m-2}}\left(\int_{0}^{T}\left|x^{\prime}(t)\right|^{m} d t\right)^{\frac{m-1}{m}} \\
& +\beta T^{\frac{m-1}{m}}\left(\int_{0}^{T}\left|x^{\prime}(t)\right|^{m} d t\right)^{\frac{1}{m}}+|e|_{\frac{m}{m-1}}\left(\int_{0}^{T}\left|x^{\prime}(t)\right|^{m} d t\right)^{\frac{1}{m}} \\
= & \frac{\alpha T^{m-1}}{2^{m-1}} \int_{0}^{T}\left|x^{\prime}(t)\right|^{m} d t+\frac{\alpha D m T^{\frac{(m-1)}{m}}}{2^{m-2}}\left(\int_{0}^{T}\left|x^{\prime}(t)\right|^{m} d t\right)^{\frac{m-1}{m}} \\
& +\left(\left|g_{B}\right| \frac{m}{m-1}+\beta T^{\frac{m-1}{m}}+|e|_{\frac{m}{m-1}}\right)\left(\int_{0}^{T}\left|x^{\prime}(t)\right|^{m} d t\right)^{\frac{1}{m}} .
\end{aligned}
$$

Since $\sigma-\frac{\alpha T^{m-1}}{2^{m-1}}>0$, so it is easy to see that there is a constant $M_{1}^{\prime}>0$ (independent of $\lambda$ ) such that

$$
\int_{0}^{T}\left|x^{\prime}(t)\right|^{m} d t \leq M_{1}^{\prime}
$$

By applying Hölder's inequality and (2.9), we have

$$
|x|_{0} \leq D+\frac{1}{2} \int_{0}^{T}\left|x^{\prime}(s)\right| d s \leq D+\frac{1}{2} T^{\frac{m-1}{m}}\left(\int_{0}^{T}\left|x^{\prime}(t)\right|^{m} d t\right)^{\frac{1}{m}} \leq D+\frac{1}{2} T^{\frac{m-1}{m}}\left(M_{1}^{\prime}\right)^{\frac{1}{m}}:=M_{1} .
$$

In view of (2.4) and $\left(\mathrm{H}_{3}\right)$, we have

$$
\begin{aligned}
\left|\phi\left(x^{\prime}\right)\right|_{0} & =\max _{t \in[0, T]}\left\{\left|\phi\left(x^{\prime}(t)\right)\right|\right\} \\
& =\max _{t \in\left[t_{0}, t_{0}+T\right]}\left\{\left|\int_{t_{0}}^{t}\left(\phi\left(x^{\prime}(s)\right)\right)^{\prime} d s\right|\right\} \\
& \leq \int_{0}^{T}\left|f\left(t, x^{\prime}(t)\right)\right| d t+\int_{0}^{T}|g(t, x(t))| d t+\int_{0}^{T}|e(t)| d t \\
& \leq \rho \int_{0}^{T}\left|x^{\prime}(t)\right|^{m-1} d t+\gamma T+T^{\frac{1}{m}}\left(\int_{0}^{T}|g(t, x(t))|^{\frac{m}{m-1}} d t\right)^{\frac{m-1}{m}}
\end{aligned}
$$




$$
\begin{aligned}
& +T^{\frac{1}{m}}\left(\int_{0}^{T}|e(t)|^{\frac{m}{m-1}} d t\right)^{\frac{m-1}{m}} \\
\leq & \rho T^{\frac{1}{m}}\left(\int_{0}^{T} \mid x^{\prime}(t)^{m} d t\right)^{\frac{m-1}{m}}+\gamma T+T^{\frac{1}{m}}\left(\int_{0}^{T}|g(t, x(t))|^{\frac{m}{m-1}} d t\right)^{\frac{m-1}{m}} \\
& +T^{\frac{1}{m}}\left(\int_{0}^{T}|e(t)|^{\frac{m}{m-1}} d t\right)^{\frac{m-1}{m}} \\
\leq & \rho T^{\frac{1}{m}}\left(M_{1}^{\prime}\right)^{\frac{m-1}{m}}+\gamma T+T^{\frac{1}{m}}\left|g_{M_{1}}\right|_{\frac{m-1}{m}}+T^{\frac{1}{m}}|e|_{\frac{m-1}{m}}:=M_{2}^{\prime},
\end{aligned}
$$

where $\left|g_{M_{1}}\right|=\max _{|x(t)| \leq M_{1}}|g(t, x(t))|$.

Thus, from Lemma 2.2, we know that there exists some positive constant $M_{2}>M_{2}^{\prime}+1$ such that, for all $t \in \mathbb{R}$,

$$
\left|x^{\prime}(t)\right| \leq M_{2} .
$$

Set $M=\sqrt{M_{1}^{2}+M_{2}^{2}}+1$, we have

$$
\Omega=\left\{\left.x \in C_{T}^{1}(\mathbb{R}, \mathbb{R})|| x\right|_{0} \leq M+1,\left|x^{\prime}\right|_{0} \leq M+1\right\},
$$

we know that (2.4) has no solution on $\partial \Omega$ as $\lambda \in(0,1)$ and when $x(t) \in \partial \Omega \cap \mathbb{R}, x(t)=M+1$ or $x(t)=-M-1$, from (2.11) we know that $M+1>D$. So, from $\left(\mathrm{H}_{1}\right)$ we see that

$$
\begin{aligned}
& \frac{1}{T} \int_{0}^{T}\{g(t, M+1)-e(t)\} d t<0, \\
& \frac{1}{T} \int_{0}^{T}\{g(t,-M-1)-e(t)\} d t>0 .
\end{aligned}
$$

So condition (ii) is also satisfied. Set

$$
H(x, \mu)=\mu x-(1-\mu) \frac{1}{T} \int_{0}^{T}\{g(t, x)-e(t)\} d t,
$$

where $x \in \partial \Omega \cap \mathbb{R}, \mu \in[0,1]$, we have

$$
x H(x, \mu)=\mu x^{2}-(1-\mu) x \frac{1}{T} \int_{0}^{T}\{g(t, x)-e(t)\} d t>0,
$$

and thus $H(x, \mu)$ is a homotopic transformation and

$$
\begin{aligned}
\operatorname{deg}\{F, \Omega \cap \mathbb{R}, 0\} & =\operatorname{deg}\left\{-\frac{1}{T} \int_{0}^{T}\{g(t, x)-e(t)\} d t, \Omega \cap \mathbb{R}, 0\right\} \\
& =\operatorname{deg}\{x, \Omega \cap \mathbb{R}, 0\} \neq 0 .
\end{aligned}
$$

So condition (iii) is satisfied. In view of Lemma 2.1, there exists at least one solution with period $T$.

Suppose that $x(t)$ is the $T$-periodic solution of (1.1). We can easily show that (2.8) also holds. Thus,

$$
x(t) \geq \min _{t \in[0, T]} x(t)=x(\underline{t})>0 \quad \text { for all } t \in \mathbb{R},
$$


which implies that (1.1) has a unique positive solution with period $T$. This completes the proof.

We illustrate our results with some examples.

Example 2.1 Consider the following second-order $p$-Laplacian-like Rayleigh equation:

$$
\left(\phi_{p}\left(x^{\prime}(t)\right)\right)^{\prime}+\left(10+5 \sin ^{2} t\right) x^{\prime}(t)-\left(5 x(t)+\sin ^{2} t-8\right)=e^{\cos ^{2} t},
$$

where $\phi_{p}(u)=|u|^{p-2} u$.

Comparing (2.12) to (1.1), we see that $g(t, x)=-5 x(t)-\sin ^{2} t+8, f(t, u)=\left(10+5 \sin ^{2} t\right) u$, $e(t)=e^{\cos ^{2} t}, T=\pi$. Obviously, we know that $\phi_{p}$ is a homeomorphism from $\mathbb{R}$ to $\mathbb{R}$ satisfying $\left(\mathrm{A}_{1}\right)$ and $\left(\mathrm{A}_{2}\right)$. Consider $\left(x_{1}-x_{2}\right)\left(g\left(t, x_{1}\right)-g\left(t, x_{2}\right)\right)=-5\left(x_{1}-x_{2}\right)^{2}<0$ for $x_{1} \neq x_{2}$, then $\left(\mathrm{A}_{3}\right)$ holds. Moreover, it is easily seen that there exists a constant $D=2$ such that $\left(\mathrm{H}_{1}\right)$ holds. Consider $f(t, u) u=\left(10+5 \sin ^{2} t\right) u^{2} \geq 10 u^{2}$, here $\sigma=10, m=2$, and $|f(t, u)|=$ $\left|\left(10+5 \sin ^{2} t\right) u\right| \leq 15|u|+1$, here $\rho=15, \gamma=1$. So, we can get that conditions $\left(\mathrm{H}_{2}\right)$ and $\left(\mathrm{H}_{3}\right)$ hold. Choose $B>0$, we have $|g(t, x)| \leq 5|x|+9$, here $\alpha=5, \beta=9$, then $\left(\mathrm{H}_{4}\right)$ holds and $\sigma-\frac{\alpha T}{2}=10-\frac{5 \pi}{2}>0$. So, by Theorem 2.1, we can get that (2.12) has a unique positive periodic solution.

Example 2.2 Consider the following second-order $p$-Laplacian-like Rayleigh equation:

$$
\left(\phi\left(x^{\prime}(t)\right)\right)^{\prime}+\left(200+16 \cos ^{2} t\right)\left(x^{\prime}(t)\right)^{3}-\left(20 x^{3}(t)+10 \cos ^{2}(t)-15\right)=e^{\sin ^{2} t}
$$

where $\phi(u)=u e^{|u|^{2}}$.

Comparing (2.13) to (1.1), we see that $g(t, x)=-20 x^{3}-10 \cos ^{2} t+15, f(t, v)=(200+$ $\left.16 \cos ^{2} t\right) v^{3}, e(t)=e^{\sin ^{2} t}, T=\pi$. Obviously, we get

$$
\left(x e^{|x|^{2}}-y e^{|y|^{2}}\right)(x-y) \geq\left(|x| e^{|x|^{2}}-|y| e^{|y|^{2}}\right)(|x|-|y|) \geq 0
$$

and

$$
\phi(x) \cdot x=|x|^{2} e^{|x|^{2}}
$$

So, we know that $\left(\mathrm{A}_{1}\right)$ and $\left(\mathrm{A}_{2}\right)$ hold. Consider $\left(x_{1}-x_{2}\right)\left(g\left(t, x_{1}\right)-g\left(t, x_{2}\right)\right)=-20\left(x_{1}-\right.$ $\left.x_{2}\right)^{2}\left(x_{1}^{2}+x_{1} x_{2}+x_{2}^{2}\right)<0$ for $x_{1} \neq x_{2}$, then $\left(\mathrm{A}_{3}\right)$ holds. Moreover, it is easily seen that there exists a constant $D=1$ such that $\left(\mathrm{H}_{1}\right)$ holds. Consider $f(t, v) v=\left(200+16 \cos ^{2} t\right) v^{4} \geq 200 v^{4}$, here $\sigma=200, m=4$, and $|f(t, v)|=\left|\left(200+16 \cos ^{2} t\right) v^{3}\right| \leq 216|v|^{3}+5$, here $\rho=216, \gamma=5$. So, we can get that conditions $\left(\mathrm{H}_{2}\right)$ and $\left(\mathrm{H}_{3}\right)$ hold. Choose $B>0$, we have $|g(t, x)| \leq$ $20|x|^{3}+25$, here $\alpha=20, \beta=25$, then $\left(\mathrm{H}_{4}\right)$ holds and $\sigma-\frac{\alpha T^{m-1}}{2^{m-1}}=200-\frac{20 \times \pi^{3}}{2^{3}}>0$. Therefore, by Theorem 2.1, we know that (2.13) has a unique positive periodic solution. 


\section{Author details}

${ }^{1}$ College of Computer Science and Technology, Henan Polytechnic University, Jiaozuo, 454000, China. ${ }^{2}$ School of Mathematics and Information Science, Henan Polytechnic University, Jiaozuo, 454000, China.

\section{Acknowledgements}

Research is supported by the National Natural Science Foundation of China (Nos. 11326124, 11271339).

Received: 31 March 2014 Accepted: 30 June 2014 Published: 15 Aug 2014

\section{References}

1. Cheung, WS, Ren, JL: Periodic solutions for p-Laplacian Rayleigh equations. Nonlinear Anal. TMA 65, 2003-2012 (2006)

2. Cheng, ZB, Ren, JL: Periodic solutions for a fourth-order Rayleigh type $p$-Laplacian delay equation. Nonlinear Anal. TMA 70, 516-523 (2009)

3. Feng, L, Guo, LX, Lu, SP: New results of periodic solutions for Rayleigh type $p$-Laplacian equation with a variable coefficient ahead of the nonlinear term. Nonlinear Anal. TMA 70, 2072-2077 (2009)

4. Ma, TT: Periodic solutions of Rayleigh equations via time-maps. Nonlinear Anal. TMA 75, 4137-4144 (2012)

5. Lu, SP, Gui, ZJ: On the existence of periodic solutions to $p$-Laplacian Rayleigh differential equation with a delay. J. Math. Anal. Appl. 325, 685-702 (2007)

6. Liang, RX: Existence and uniqueness of periodic solution for forced Rayleigh type equations. J. Appl. Math. Comput. 40, 415-425 (2012)

7. Xiao, B, Liu, W: Periodic solutions for Rayleigh type $p$-Laplacian equation with a deviating argument. Nonlinear Anal., Real World Appl. 10, 16-22 (2009)

8. Wang, LJ, Shao, JY: New results of periodic solutions for a kind of forced Rayleigh-type equation. Nonlinear Anal., Real World Appl. 11, 99-105 (2010)

9. Xiong, WM, Shao, JY: Existence and uniqueness of positive periodic solutions for Rayleigh type $p$-Laplacian equation. Nonlinear Anal., Real World Appl. 10, 275-280 (2009)

10. Zong, MG, Liang, HZ: Periodic solutions for Rayleigh type $p$-Laplacian equation with deviating arguments. Appl. Math. Lett. 20, 43-47 (2007)

11. Manásevich, R, Mawhin, J: Periodic solutions for nonlinear systems with p-Laplacian-like operator. J. Differ. Equ. 145, 367-393 (1998)

10.1186/1687-1847-2014-225

Cite this article as: Xin and Cheng: Existence and uniqueness of a positive periodic solution for Rayleigh type $\phi$-Laplacian equation. Advances in Difference Equations 2014, 2014:225

\section{Submit your manuscript to a SpringerOpen ${ }^{\circ}$ journal and benefit from:}

- Convenient online submission

- Rigorous peer review

- Immediate publication on acceptance

- Open access: articles freely available online

- High visibility within the field

- Retaining the copyright to your article 